\title{
Complete Tumor Cell Necrosis
}

National Cancer Institute

\section{Source}

National Cancer Institute. Complete Tumor Cell Necrosis. NCI Thesaurus. Code C156234.

A morphologic finding indicating the presence of tumor cell necrosis involving the entire neoplastic cellular infiltrate in a tissue sample. Viable tumor cells are absent. 